\title{
AN UPDATE ON GERIATRIC PNEUMONIA- CONTEMPORARY REVIEW ON PNEUMONIA IN OLD AGED
}

\author{
S. A. Rafi', Pullarao P2, Anzala Kauser ${ }^{3}$ \\ ${ }^{1}$ Consultant Pulmonologist, Department of Pulmonary Medicine, Care Hospitals, Hyderabad, Telangana, India. \\ ${ }^{2}$ Senior Resident, Department of Pulmonary Medicine, Care Hospitals, Hyderabad, Telangana, India. \\ 3Medical Student, ESIC Medical College, Hyderabad, Telangana, India.
}

\section{ABSTRACT}

\section{BACKGROUND}

Pneumonia represents the third most frequent hospital diagnosis among elderly patients. They usually have associated comorbid conditions and immunosuppressive states, hence predisposed to pneumonia. Furthermore, it has been suggested that elderly patients treated for pneumonia are at high risk of subsequent mortality for several years after the episode. Thus, due to its high incidence and significant mortality, it has become a major public health problem. Investigating strategies to reduce mortality in these patients should be a major issue for future research. To date, however, there is little information on pneumonia in patients over the age of 65 years. The goals of the current article are to review the existing literature about the epidemiology, causative organisms, clinical characteristics, management and prevention of pneumonia in the geriatric population and to identify cause s of death and risk factors associated with mortality. In this population, an aetiological diagnosis is rarely available when antimicrobial therapy must be instituted. Use of the current guidelines for treatment of pneumonia with special emphasis on vaccination for its prevention is recommended in this population.

\section{KEY WORDS}

Geriatric, Pneumonia, Elderly, Old Age, Prevention, Vaccination.

HOW TO CITE THIS ARTICLE: Rafi SA, Pullarao P, Kauser A. An update on geriatric pneumonia- contemporary review on pneumonia in old aged. J. Evolution Med. Dent. Sci. 2018;7(44):4802-4811, DOI: 10.14260/jemds/2018/1070

\section{BACKGROUND}

Achieving age 65 years or older is generally defined as elderly in developed countries and in the medical literature. Because of the aging process, elderly individuals display gradual organ system functional decline that is likely linked to cumulative damage to molecules, cells and tissues that occurs over a life time. However, there are considerable interindividual differences in the rate of decline. Some people maintain robust physiologic function well beyond their $6^{\text {th }}$ decade of life, whereas others may be seriously challenged by progressive organ system dysfunction and frailty as they age.

\section{Definition}

Pneumonia is defined as inflammation and consolidation of lung tissue due to an infectious disease. Clinically, pneumonia is characterised by a variety of symptoms and signs.

A clinical definition of pneumonia is two or more of the following symptoms/ physical findings: Productive cough, purulent sputum, dyspnoea or tachypnoea (Respiratory rate $>20$ breaths per minute), rigors or chills, pleuritic chest pain in conjunction with a new opacity on chest radiograph.(1) Pneumonia that develops outside the hospital is considered Community-Acquired Pneumonia (CAP). Pneumonia developing 72 hours or more after admission to hospital is nosocomial or hospital acquired. It is important to remember that pneumonia in the elderly may present with few respiratory symptoms and signs, instead they may manifest as delirium, worsening of chronic confusion and falls.

'Financial or Other Competing Interest': None.

Submission 13-12-2017, Peer Review 09-10-2018,

Acceptance 16-10-2018, Published 29-10-2018.

Corresponding Author:

Dr. S. A. Rafi,

612, Manara Block

Garden Towers, Masab Tank

Hyderabad-500028, Telangana, India.

E-mail:drrafishaik@gmail.com

DOI: $10.14260 /$ jemds $/ 2018 / 1070$

\section{(c) $($ ) $€$}

\section{Epidemiology}

Pneumonia is a common and often serious illness. Recovery is prolonged in the elderly, especially the frail elderly who may require upto several months to return to their baseline state of mobility. Indeed, hospitalisation with its enforced immobility often hastens functional decline in the elderly; $25 \%-60 \%$ of older patients experience a loss of independent physical function while being treated in the hospital.(2) The presence of any or all of the following identifies elderly persons at greatest risk for functional decline: decubitus ulcer, cognitive impairment, functional impairment and low level of social activity.(3) Older patients with pneumonia complain of fewer symptoms than do younger patients with pneumonia. Patients aged $45-64,65-74$ and $>75$ years had 1.4, 2.9 and 3.3 fewer symptoms than patients aged $18-44 .(4)$ The incidence of pneumonia is highest at the extremes of age. Jokinen et al studied all patients with suspected or confirmed pneumonia among 46,979 inhabitants of 4 municipalities in the province of Kuopio, Finland and found that the agespecific incidences per 1000 inhabitants were 36.0 for those aged $<5$ years; 16.2 for those aged 5 - 14 years; 6.0 for those aged 15 - 59 years; 15.4 for those aged 60 - 74 years; and 34.2 for those aged $>75$ years. In another population-based study in a Finnish town, Koivula et al(5) found that each year 14 per 1000 persons $>60$ years of age developed pneumonia. $75 \%$ of these cases were CAP. It is interesting to examine the mean age of patients who require hospitalisation for treatment of CAP over the past several decades. Dorff et al(6) studied 148 consecutive patients with pneumonia and found that "patients tended to be elderly" (mean age, 55 years). In contrast, a study in Halifax, Nova Scotia showed that the mean age of the 719 patients with CAP was 63.2 years.(7) A Canadian study showed that the mean age of the 858 patients was 69.4518 years.(8) Meehan et al(9) focused on 14,069 Medicare patients aged > 65 years who required hospitalisation for CAP. They noted that $30.3 \%$ were aged 64-74 years, $41.8 \%$ were aged $75-84$ years and $27.8 \%$ were aged $>85$ years. From these observations, it is clear that most 
patients who are hospitalised with CAP are elderly. According to Janssens JP et al,(10) the annual incidence of CAP in elderly patients estimated to be 25 - 44 cases per 1000 persons. A large, population-based cohort study of elderly adults by Jackson et al further divided this population into two groups, those aged 65 - 69 years and those aged 85 years and older.(11) This study, which examined both inpatient and outpatient episodes of CAP found incidence rates of 18.2 cases per 1000 persons in the 65 - 69-year-olds group and 52.3 cases per 1000 persons in those aged at least 85 years.(11) This data suggests that even within the elderly population, those with more advanced age are more susceptible to CAP. According to Kaplan et al, adults older than 90 years of age were over five-times more likely to be hospitalised than those aged 65 - 69 years.(12) VilaCorcoles(13) et al studied the incidence rates among 11,241 cohort members and were observed for a total of 33,905 person-years. Overall, $43.5 \%$ of the subjects were male, $55.2 \%$ were 65 - 74 years old, $34.3 \%$ were 75 - 84 years old and $10.5 \%$ were aged 85 years or older at the beginning of the study. Maximum incidences were observed among patients with chronic lung disease and long-term corticosteroid therapy (46.5 and 40.1 cases per 1000 personyears, respectively).

Mortality rates in the elderly with CAP are higher than in younger populations. The recent data revealed mortality rates ranging from 10 to $30 \%$ in those aged 65 years or older.(10,14) A recent study by Kothe et al confirms these findings, demonstrating that age itself was associated with increased mortality in CAP.(14)

Despite the recognised importance of CAP in the elderly, information on its epidemiology in this age group is limited. Most epidemiological data has been obtained from studies on CAP patients admitted in hospitals $(7,15-17)$ and few studies focusing on the possible contribution of outpatient cases have been reported.(11,18,19) Regarding the prevalence of pneumonia in India, the situation is not different from the rest of the world. No proper field surveys have been conducted in India so far to generate concrete data for epidemiology in this age group.

\section{Risk Factors}

The risk factors for CAP are mentioned in Table 1.

\begin{tabular}{|c|c|}
\hline Immunocompetent at risk & Immunocompromised at risk \\
\hline $\begin{array}{l}\text { Age } \\
\text { Lifestyle } \\
\text { - Alcoholism } \\
\text { - Smoking } \\
\text { Underlying diseases } \\
\text { - Chronic heart disease } \\
\text { - Chronic renal disease } \\
\text { - Chronic liver disease } \\
\text { - Chronic respiratory disease } \\
\text { - Metabolic disease } \\
\text { - CNS disease } \\
\text { Prior IPD } \\
\text { Previous pneumonia } \\
\text { Other } \\
\text { - Aspiration } \\
\text { - Concomitant treatment }\end{array}$ & $\begin{array}{l}\text { - Immunosuppression } \\
\text { - Autoimmune diseases receiving steroid or immunosuppressive therapy or biological therapy } \\
\text { - Cancer with immunosuppressive treatment } \\
\text { - Waiting list for solid-organ transplantation (with or without immunosuppressive treatment) } \\
\text { - Other immunosuppression } \\
\text { - Immunocompromised } \\
\text { - Asplenia/splenic dysfunction } \\
\text { - Primary immunodeficiencies } \\
\text { - HIV }\end{array}$ \\
\hline
\end{tabular}

\section{Lifestyle Factors and Risk of CAP}

The potential association between lifestyle factors and the risk of CAP was investigated in 12 case control studies. $(20,21)$ There was consistent evidence that smoking was associated with an increased risk of CAP.(20-24) Alcohol consumption was associated with CAP. Being underweight was generally associated with an increased risk of Pneumonia(22-25) compared with normal bodyweight. Household arrangements were also associated with the risk of Pneumonia. Living in a household of over 10 people was associated with increased risk. Higher levels of education were associated with a lower risk of CAP.(23-25) Two studies found that visiting the dentist was associated with a decreased risk of CAP.(24)

\section{Environmental Factors}

There is a clear seasonal variation in the rate of pneumonia; both attack rates and mortality rates are highest in the winter months.(26)

\section{Comorbid Conditions and Risk of CAP}

The association between comorbidities and the risk of CAP was investigated in 14 case-control studies.(20,21,27,28) A history of respiratory disease was associated with an increased risk of CAP. A history of pneumonia increased the risk of a subsequent episode.(24,25) Patients with chronic respiratory diseases including COPD, bronchitis or asthma, had a two-fold to four-fold increase in the risk of CAP.(2225,27,29) Chronic cardiovascular disease increased the risk of CAP upto three-fold.(22,24,25,28,29) Cerebrovascular disease/stroke and dementia approximately doubled the risk of CAP (for cerebrovascular disease/ stroke).(20,21,27) Other neurological or psychiatric conditions were also associated with an increased risk of CAP in some studies (epilepsy), (24) Parkinson's disease(27) and multiple sclerosis. Two studies in elderly patients found a strong association between dysphagia and risk of CAP.(27,29) Data from several studies suggested that diabetes mellitus was associated with a moderate increase in the risk of CAP.(24) Cancer was also 
associated with a moderate increase in the risk of CAP. Chronic liver or renal disease increased the risk of CAP approximately two-fold.(24,25) Associations between conditions affecting immune function and the risk of CAP were reported. There was a moderate increase in risk in patients with rheumatoid arthritis. Additionally, there was over a two-fold increase in risk in patients with asplenia or with HIV or AIDS. In addition to the above medical conditions, a moderate increase in risk of CAP was reported in patients with anaemia. The risk of CAP was increased in patients who had undergone either bronchoscopy or passage of a nasogastric tube during the previous year.(24)

The Risk Factors for Nursing Home Acquired Pneumonia are as follows

\begin{tabular}{|c|c|}
\hline 1. & Profound disability \\
\hline 2. & Bedridden \\
\hline 3. & Urinary incontinence or deteriorating health status \\
\hline 4. & Old age \\
\hline 5. & Male sex \\
\hline 6. & Difficulty in swallowing \\
\hline 7. & Inability to take oral medications \\
\hline
\end{tabular}

\section{Aetiology}

Although, there are well over 100 microorganisms that can cause pneumonia, only a few (S. pneumoniae, Haemophilus influenzae, S. aureus, C. pneumoniae, Enterobacteriaceae, Legionella species, influenza viruses and respiratory syncytial virus) cause most of the cases of pneumonia. S. pneumoniae has been previously documented as the primary aetiology of CAP in the elderly.(10) A compilation of data from 9 comprehensive studies of the aetiology of CAP among 5225 patients requiring hospitalisation identified S. pneumonia as the aetiologic agent in $17.7 \%$ of cases. $(7,30)$ According to Fernandez et al, S. pneumonia was the most frequent causative agent of CAP in the elderly with aspiration pneumonia as the second most common cause.

The frequency of S. pneumoniae in patients with NHAP in the elderly population remains controversial. El-Solh AA et al studied intubated patients of $>75$ years old with NHAP or with CAP and found that S. aureus (29\%) surpassed S. pneumoniae $(9 \%)$ as the leading pathogenic agent of NHAP.(31) Based on these previous data obtained from intubated patients, the ATS/ IDSA guidelines suggest that the prevalence of S. pneumoniae is low in NHAP and that NHAP and HAP have a common aetiology.(32) In 6 studies of 471 patients with nursing home-acquired pneumonia, $\mathrm{S}$. pneumoniae accounted for most $(12.9 \%)$ of the cases followed by H. influenzae (6.4\%), S. aureus (6.4\%), Moraxella catarrhalis $(4.4 \%)$ and aerobic gram negative bacilli (13.1\%).[32-35] Outbreaks of C. pneumoniae infection among the elderly in nursing homes have frequently been reported.(35) According to the recent study conducted by Maruyama et al in Japan C. pneumoniae was the commonest aetiology of pneumonia in the very elderly with low frequency of infection caused by bacterial pathogens of the enterobacteriaceae and anaerobes group.(36) The aetiology of nursing home-acquired pneumonia is not well established, since these studies have relied almost entirely on the results of sputum cultures. Colonisation of the oropharyngeal mucosa with aerobic gram negative bacilli increases with increasing age and is especially common among residents of nursing homes.(37) Viral infection in nursing homes is usually seasonal. According to the recent study conducted by Maruyama et al in Japan, infection with influenza virus is seen in $88.9 \%$ of NHAP that occur between November and March. CMV can also be a causative agent of pneumonia.(38)

Nursing home residents account for $20 \%$ of cases of tuberculosis in older people.(39) The incidence of active tuberculosis among nursing home patients is 10 - 30 times greater than among elderly adults( ${ }^{(37)}$ living in the community.

\section{Clinical Presentation}

In older patients the pneumonia process often extends beyond the lung parenchyma, presenting as a systemic disease with higher severity of illness. This is supported by the finding that many elderly CAP patients present with primarily non-pulmonary symptoms, such as mental status changes or renal dysfunction. The usual symptoms of fever, chills, rigors and sputum production that are present in young adults all may be absent; confusion may be the only presenting symptom. Tachypnoea is frequent, but the physical examination, in addition to often being technically difficult is not sufficiently sensitive in making a diagnosis.(40)

\section{Management of Pneumonia in the Elderly}

\section{Severity Assessment and Criteria for ICU Admission}

Severity assessment and site-of-care decisions are critical when managing elderly patients who present with CAP. These factors have a significant impact on healthcare utilisation and often affect diagnostic work-ups, therapeutic interventions and clinical outcomes. As a result, there has been significant interest in this area of research over the past decade.

Severity assessment tools can help predict mortality and determine the optimal setting, in which to provide care for patients with CAP. The Pneumonia Severity of Illness (PSI) score and the CURB-65 are the most extensively studied and widely recommended scores for assessing patients who present with CAP. $(41,42)$ The PSI is based on 20 parameters that are evaluated at the time of clinical presentation (three demographic considerations, five comorbid conditions, five physical examination findings and seven laboratory/ imaging variables).(42) The primary purpose of the PSI score is to distinguish between patients that could be safely treated in an outpatient setting versus those inpatient observation and treatment.

The CURB-65 score places similar importance on age when assessing severity of illness. The CURB-65, a less complex scoring system, only requires six variables to be evaluated at presentation (confusion, blood urea nitrogen, respiratory rate, systolic or diastolic blood pressure and age).(43) A simplified tool derived from the CURB-65 withdraws the only laboratory value needed to calculate the score (blood urea nitrogen). This tool, termed CRB-65, showed similar results in evaluating severity of illness in CAP.(43) In both CURB-65 and CRB-65, age is an extremely significant variable that often results in higher severity indices among elderly patients presenting with CAP. The profound influence of age on PSI, CURB-65 and CRB-65 scores highlights the fact that elderly patients with CAP are at risk for higher severity of disease and therefore poorer clinical outcomes. Several tools have also been designed to predict the need for ICU admission and the risk of death in patients presenting with severe CAP. Examples include the PS- 
CURXO80, SMART-COP and PIRO-CAP score. All of these scores, except the one recommended by the guidelines, include age as one of the variables associated with poor outcomes. ${ }^{(41,44-46)}$

Recently, Rello and collaborators developed the CAPPIRO score based on a score initially used to predict the risk of sepsis and was able to consistently predict ICU mortality and healthcare utilisation in a cohort of 529 patients admitted to the ICU with CAP.(46) This score evaluates variables related to the PIRO score that include: predisposition, infection, response and organ dysfunction, in which age greater than 70 years confers one point for each of the predisposition variables. Thus, data from the most recent severity of illness assessments support the assumption that elderly patients are at increased risk for severe CAP.

In conclusion, we favour the use of the CURB-65 in order to decide when to admit a patient to the hospital and the IDSA/ ATS guidelines major and minor criteria to assist in the decision to admit a patient to the ICU.

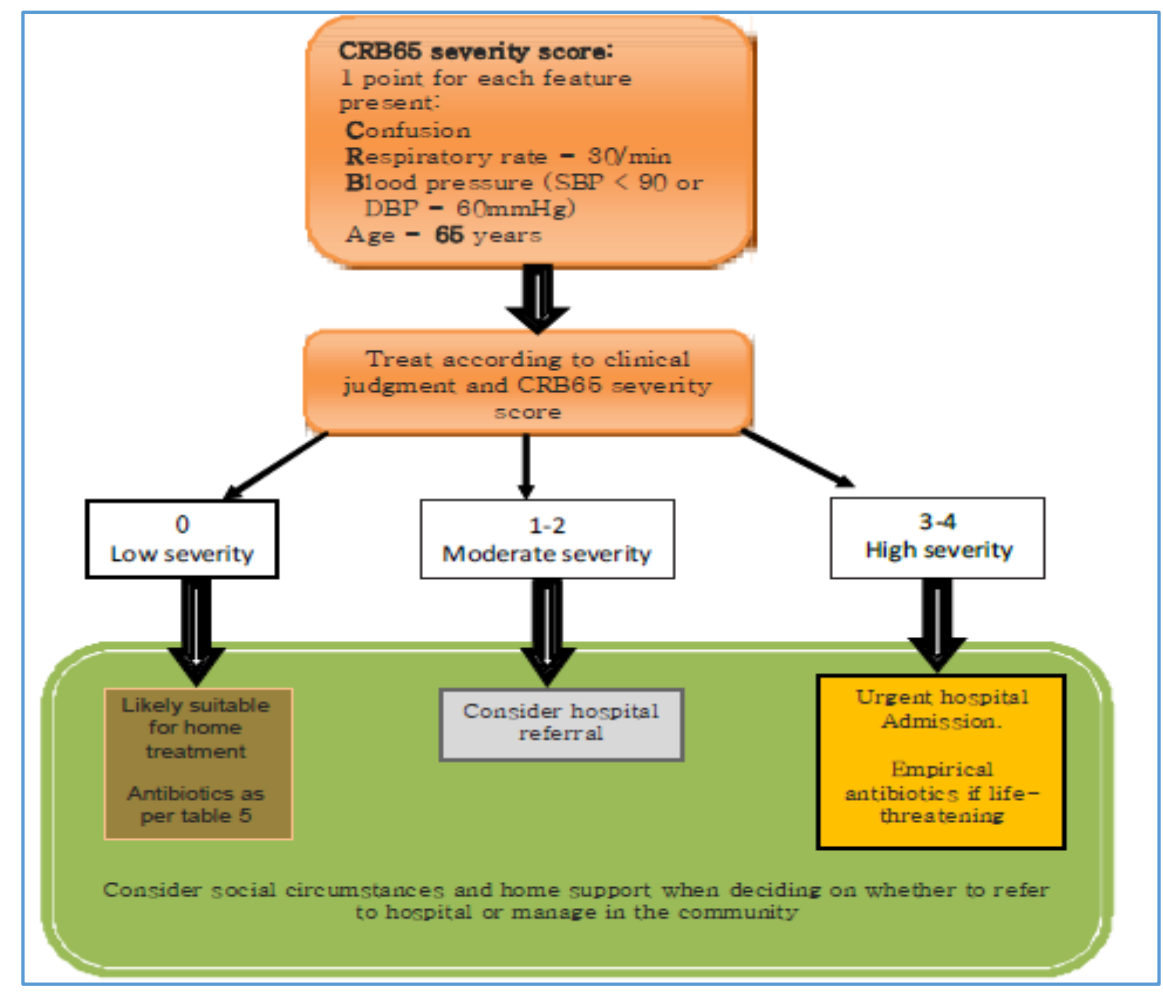

\section{Diagnostic Workup}

The extent of the diagnostic workup for patients with pneumonia depends upon the severity of pneumonia. For otherwise healthy patients who are going to be treated on an ambulatory basis, a chest radiograph to confirm the clinical diagnosis is all that is necessary; however, for elderly patients, who often have comorbidities for which they are receiving medication, a complete blood cell count and measurements of electrolytes and serum creatinine are usually indicated.

All patients who require admission to the hospital for treatment of CAP should undergo chest radiography. All patients who are admitted to the hospital should have blood cultures performed, even though only $6 \%-10 \%$ of patients with CAP will be bacteraemic. $(7,30)$ The reason for this recommendation is that a blood culture positive for pathogen is definite evidence that the microorganism is causing the pneumonia. Gram staining of a good sputum specimen $(<10$ squamous epithelial cells per low-powered field; $>25$ WBCs per low-powered field) is useful for directing initial antibiotic therapy (e.g. a good specimen that is gram-positive for diplococci suggests a diagnosis of pneumococcal pneumonia, thus allowing more specific antibiotic therapy); thus, an attempt should be made to collect such a specimen.
The limitations of expectorated sputum must be recognised by the clinician, especially for the elderly, in whom oropharyngeal colonisation with aerobic gramnegative bacilli is common, so that differentiating colonisation from infection may be difficult. Bronchoscopy is not uncommonly performed on patients with pneumonia who require admission to an intensive care unit. In such instances, samples of lower respiratory tract secretions should be obtained with a protected bronchial brush or BAL. Rarely, an open-lung biopsy is required.

\section{Bronchoscopic Samples}

The reliability of bronchoscopic procedures to determine the microbial aetiology of pneumonia depends on the technique used and the organism sought. When compared with sputum cultures, optimally processed bronchoscopic specimens demonstrate improved sensitivity and equal specificity for the culture of pathogenic fungi and mycobacteria. Semiquantitative or quantitative cultures of materials obtained bronchoscopically with a protected sheath brush or through Bronchoalveolar Lavage (BAL) and by direct lung aspiration have been successfully used for aerobic and anaerobic bacterial cultures.(47) BAL fluid can be quantitatively cultured for bacteria and qualitatively cultured for fungi, mycobacteria and viruses. ${ }^{(48)}$ 
BAL permits identification of contaminated specimens (i.e. those with $>1 \%$ squamous epithelial cells), the immediate diagnosis of infection (i.e. intracellular bacteria in more than $2 \%$ to $5 \%$ of examined polymorphonuclear leukocytes), and the exclusion of infection (i.e. the absence of bacterial pathogens in culture of BAL fluid, although the sensitivity is reduced by prior antibiotic administration).(49)

Serological studies are not recommended routinely. However, if certain aetiologic agents such as Coxiella burnetii, M. pneumoniae, C. pneumoniae or a virus are suspected, serological tests of acute and convalescent serum samples can aid in the diagnosis. Unfortunately, the results of these studies are not available for $3-4$ weeks, by which time the clinical situation has been resolved. These studies are helpful for public health purposes and should always be performed in workups during an outbreak of pneumonia. A urine specimen for detection of Legionella antigen is useful in all cases of severe pneumonia. PCR has been used to amplify DNA of various pneumonia pathogens from nasopharyngeal samples, lung tissue samples and WBCs. Currently, PCR is not recommended for routine use.

\section{Differential Diagnosis}

\begin{tabular}{|c|c|}
\hline 1. & Tuberculosis \\
\hline 2. & Malignancy \\
\hline 3. & Pulmonary oedema \\
\hline 4. & Pulmonary embolism \\
\hline 5. & Pulmonary haemorrhage \\
\hline 6. & ARDS \\
\hline 7. & Cryptogenic organising pneumonia \\
\hline 8. & Systemic vasculitis/ connective tissue disease \\
\hline 9. & Eosinophilic pneumonia \\
\hline 10. & Sarcoidosis \\
\hline 11. & Drug-induced lung disease \\
\hline 12. & \\
\hline
\end{tabular}

\section{Therapeutic Approach to Pneumonia}

Antimicrobials are the cornerstone of therapy for CAP in any population including the elderly. In addition, some nonantibiotic strategies may be important when treating CAP in elderly populations. The following discussion will focus on both the antibiotic and non-antibiotic therapies for elderly patients with CAP.

\section{Antibiotic Therapies}

The treatment of pneumonia in the elderly is clearly based on the use of antibiotic therapy, but limited data are available regarding the specific treatments for elderly patients with CAP. Therefore, we will attempt to summarise the most relevant and critical data published in this specific age group. The most recently published clinical practice guidelines do not recommend different treatments for elderly patients, who are included in the general treatment recommendations for CAP.(57) Our group supports the current guidelines with modifications based on the recent data regarding the management of elderly with CAP.

The most recent clinical practice guidelines emphasise the importance of appropriate, aggressive and early treatment of elderly patients with CAP.(41) The latest guidelines suggest that the treatment approach should be stratified according to the location of therapy as outpatient or in the hospital, whether in the ward service or the ICU setting.(41) Therefore, elderly patients managed as outpatient should receive antibiotics that have coverage for the most likely pathogens such as S. pneumoniae, H. influenzae, M. pneumoniae and C. pneumoniae. The treatment should include a macrolide or doxycycline. Those admitted to the ward should be covered with a respiratory fluoroquinolone (Levofloxacin or moxifloxacin) as monotherapy or the combination of a $\beta$-lactamic (Third-generation cephalosporin, ertapenem or ampicillin/ sulbactam) medication and a macrolide (Azithromycin or clarithromycin). In addition to the pathogens usually present in the ward service, elderly patients admitted to the ICU should be evaluated for risk of infection with Pseudomonas species. The most commonly accepted risk factor for Pseudomonas species is structural lung diseases (e.g. bronchiectasis). Those elderly ICU patients without pseudomonas risk factors should be treated with a $\beta$ lactam and the addition of an antibiotic with good atypical coverage (particularly for Legionella species), such as macrolides or respiratory fluoroquinolones. However, if Pseudomonas pneumonia is considered likely, empiric coverage should focus on its treatment without losing coverage for Legionella and Pneumococcus. The recommended treatment in this setting includes empiric antibiotic therapy with an antipseudomonal $\beta$-lactam plus an antipseudomonal fluoroquinolone. The use of an antipseudomonal $\beta$-lactam and a macrolide is also an acceptable empiric therapy. Aminoglycosides are not particularly good for lung infections in elderly patients owing to the risks of nephrotoxicity and ototoxicity, but are advised in critically ill patients with risk factors for Pseudomonas pneumonia. As with all infections, specific therapy should be tailored as specific pathogens are isolated. This point is even more important in elderly patients who may be at increased risk for medication interactions and adverse medication effects.

To our knowledge, only a few studies have been published since 2006 regarding the treatment of elderly patients with CAP. Anzueto and colleagues conducted a randomised, controlled trial comparing moxifloxacin $(n=195)$ versus levofloxacin $(n=199)$ in hospitalised elderly patients ( $\geq 65$ years). ${ }^{(50)}$ The authors concluded that moxifloxacin therapy was as efficacious (Clinical cure rate $\geq 90 \%$ in all severity and age subgroups) and as safe as levofloxacin in elderly patients with CAP. Nonetheless, caution must be exercised when using any fluoroquinolone or macrolide in patients with known prolongation of the QT interval, hypokalaemia, hypomagnesaemia and patients receiving class IA (e.g. quinidine and procainamide) or class III (e.g. amiodarone and sotalol) antiarrhythmic agents. (51)

Empiric antibiotic therapy focusing on CA-MRSA is still not consistently recommended by the latest clinical practice guidelines, but there is a great concern regarding the higher incidence of CA-MRSA reported in the community.(41,52) The authors recommend considering CA-MRSA pneumonia coverage in patients that present with the following risk factors: rapid presentation and progression of a cavitating pneumonia, high severity of disease, associated influenza infection or associated skin lesions consistent with MRSA infections. In these settings, coverage should include empiric vancomycin or linezolid with the possibility that linezolid may be more appropriate coverage owing to inhibition of toxin production and increasing vancomycin minimum inhibitory concentrations among MRSA isolates. ${ }^{(41,52)}$ 
Recent data suggested that combination therapy with a $\beta$ lactam and a macrolide was associated with favourable outcomes in hospitalised and ICU patients with $\operatorname{CAP}(53,54)$ and bacteraemic pneumococcal pneumonia. $(53,55,56)$ The beneficial effect observed with the macrolides may be owing to their immunomodulatory properties, but more data are needed to support this hypothesis. Therefore, we suggest clinicians to follow the latest clinical practice guideline recommendations, $(41)$ owing to the significant number of studies supporting the benefit in clinical practice with improved clinical outcomes. (57-60) The impact of following the clinical practice guidelines for the management of CAP has shown improvement in the quality and efficiency of care and decreased mortality.(57-60)

Antibiotic recommendations for nosocomial pneumonia are not different for elderly. So, we suggest the same current guidelines in the geriatric population.

\begin{tabular}{|c|c|c|c|}
\hline \multicolumn{3}{|c|}{ Antibiotic Recommendations for Nosocomial Pne umonia } & \multirow[b]{2}{*}{ Additional Information } \\
\hline $\begin{array}{l}\text { Pneumonia } \\
\text { Category }\end{array}$ & Microorganisms & Empiric Therapy & \\
\hline $\begin{array}{l}\text { HCAP/HAP } / N A P \\
\text { No risk for MDR } \\
\text { pathogens and } \\
\text { hospitalized }<5 \mathrm{~d}\end{array}$ & $\begin{array}{l}\text { Streptococcus pneumonia } \\
\text { Haemophilus influenzoe } \\
\text { Methicilin-sensitive } \\
\text { Staphylococcus aureus } \\
\text { Escherichia coli } \\
\text { Klebsiella pneumoniae } \\
\text { Enterobacter species } \\
\text { Proteus species } \\
\text { Serratia marcescens }\end{array}$ & $\begin{array}{l}\text { Third-generation cephalosporin (Ceftriaxone) } \\
\text { Or } \\
\text { Ampicillin-sulbactam } \\
\text { Or } \\
\text { Respiratory fluoroquinolone (Levofloxacin or } \\
\text { Moxifloxacin) } \\
\text { Or } \\
\text { Non-antipseudomonal carbapenem (Ertapenem) }\end{array}$ & $\begin{array}{l}\text { Azithromycin should be con- } \\
\text { sidered for atypical coverage } \\
\text { in very ill patients or ones with } \\
\text { a high suspicion for atypical } \\
\text { organisms or Legionella who } \\
\text { are not on a respiratory fluoro. } \\
\text { quinolone }\end{array}$ \\
\hline $\begin{array}{l}\text { HCAP/HAP NAP } \\
\text { At risk for MDR } \\
\text { pathogens or hos- } \\
\text { pitalized for } \geq 5 \mathrm{~d}\end{array}$ & $\begin{array}{l}\text { Pseudomonas ceruginosa } \\
\text { Kebsiella pneumonia } \\
\text { (extended-spectrum } \\
\beta \text {-lactamase+) } \\
\text { Acinetobacter species } \\
\text { Legionella pneumophila } \\
\text { Nethicillin-resistant } \\
\text { S. aureus }\end{array}$ & $\begin{array}{l}\text { Antipseudomonal cephalosporin (Cefepime, Ceftazidime) } \\
\text { Or } \\
\text { Antipseudomonal carbapenem (Imipenem or Meropenem) } \\
\text { Or } \\
\text { Antipseudomonal penicillin with } \beta \text {-lactamase inhibitor } \\
\text { (Piperacillin-tazobactam) } \\
\text { Plus } \\
\text { Antipseudomonal fluoroquinolone (Ciprofloxacin or } \\
\text { Levofloxacin) } \\
\text { Or } \\
\text { Aminoglycoside (Gentamycin, Tobramycin, or Amikacin) } \\
\text { Plus } \\
\text { Anti-MRSA agent (Linezolid or Vancomycin) }\end{array}$ & $\begin{array}{l}\text { Carbapenems are often effec- } \\
\text { tive against ESBL organisms } \\
\text { (E. coli, Klebsiella) or } \\
\text { Acinetobacter species } \\
\text { For patients with penicillin } \\
\text { allergy consider substituting } \\
\text { B-lactem with: } \\
\text { - Aztreonam } \\
\text { - Meropenem ( }<1 \% \text { cross } \\
\text { reactivity to penicillin } \\
\text { allergy) } \\
\text { Inhaled antibiotics have been } \\
\text { used in selected populations } \\
\text { and should be used only aiter } \\
\text { consultation with a subspecialist }\end{array}$ \\
\hline
\end{tabular}

\section{Switch from Intravenous to Oral Therapy}

Patients should be switched from intravenous to oral therapy when they are haemodynamically stable and improving clinically, are able to ingest medications and have a normally functioning gastrointestinal tract.

Initially, Ramirez et al(61) defined a set of criteria for an early switch from intravenous to oral therapy. An alternative approach is to change from intravenous to oral therapy at a predetermined time, regardless of the clinical response.(62) Discharge should be considered when the patient is a candidate for oral therapy and when there is no need to treat any comorbid illness, no need for further diagnostic testing and no unmet social needs.(63)

In general, when switching to oral antibiotics, either the same agent as the intravenous antibiotic or the same drug class should be used. Switching to a different class of agents simply because of its high bioavailability (such as fluoroquinolone is probably not necessary for a responding patient.

\section{Duration of Antibiotic Therapy}

Patients with CAP should be treated for a minimum of 5 days, should be afebrile for 48 - $72 \mathrm{~h}$, and should have no more than one CAP-associated sign of clinical instability (Table 2) before discontinuation of therapy. A longer duration of therapy may be needed if initial therapy was not active against the identified pathogen or if it was complicated by extrapulmonary infection such as meningitis or endocarditis.

Most patients with CAP have been treated for 7 - 10 days or longer, but few well-controlled studies have evaluated the optimal duration of therapy for patients with CAP, managed in or out of the hospital. In trials of antibiotic therapy for CAP, azithromycin has been used for 3 - 5 days as oral therapy for outpatients with some reports of single-dose therapy for patients with atypical pathogen infections.(64) The ketolide telithromycin has been used for 5 - 7 days to treat outpatients including some with pneumococcal bacteraemia or PSI classes III.(65) In a recent study, high dose $(750 \mathrm{mg})$ levofloxacin therapy for 5 days was equally successful and resulted in more afebrile patients by day 3 than did the 500 mg dose for 7 - 10 days.(66)

\begin{tabular}{|c|c|}
\hline 1. & Temperature $<37.8^{\circ} \mathrm{C}$ \\
\hline 2. & Heart rate $<100$ beats $/ \mathrm{min}$ \\
\hline 3. & Respiratory rate $<24$ breaths $/ \mathrm{min}$ \\
\hline 4. & Systolic blood pressure $>90 \mathrm{mmHg}$ \\
\hline 5. & Arterial oxygen saturation $>90 \%$ or $\mathrm{pO}_{2} 60 \mathrm{mmHg}$ on \\
room air
\end{tabular}

Patients with persistent clinical instability are often readmitted to the hospital and may not be candidates for short duration therapy. Studies of duration of therapy have 
focused on patients receiving empirical treatment and reliable data defining treatment duration after an initially ineffective regimen are lacking. So, we suggest minimum of 5 days therapy when the initial antibiotic is effective against the specific pathogen and a longer duration of therapy (7 - 10 days) when the initial antibiotic is ineffective.

\section{Non-Antibiotic Therapies}

Several non-antibiotic therapies have been recommended in severely ill patients with CAP, usually those in the ICU setting. These therapies include the use of systemic corticosteroid ${ }^{67)}$ therapy for patients with severe CAP, recombinant human activated protein $\mathrm{C}^{(68)}$ for patients with severe sepsis owing to CAP with at least two organs failing and the use of lung protective-ventilation strategy(69) for patients with acute respiratory distress syndrome owing to CAP. Although, lungprotective ventilation is the standard of care in acute respiratory distress syndrome patients, the benefits of other therapies such as corticosteroids(67) or activated protein C(68) are less clear in patients with severe CAP. In addition, there is a growing body of evidence suggesting that certain immunomodulatory agents other than corticosteroids may favourably influence outcomes in patients with CAP.(70) Such immunomodulatory agents include medications such as statins and angiotensin-converting enzyme inhibitors, which have been suggested to improve outcomes in patients with pneumonia.(70) However, these studies were mainly retrospective in nature and the healthy-user bias was not controlled for; therefore, further prospective studies and randomised, controlled trials are needed before recommending them in clinical practice.

\section{Issues that are especially Significant when Treating Elderly Patients with Pneumonia \\ Functional Assessment}

It is useful to quantify the level of function of your elderly patients with use of Barthel's index and/ or the hierarchical assessment of balance and mobility.(71) The former scores 15 factors that are rated by the patient are as follows: can do by myself, can do with help of someone else and cannot do at all. The total score can range from 0 (Total dependence) to 100 (Complete independence). A score $<40$ defines those who are severely dependent, whereas a score of 41 - 60 indicates marked dependence. The hierarchical assessment of balance and mobility separates mobility into 3 categories- mobility, transfers and balance- and constructs a hierarchical range of abilities in each section.

\section{Referral to Geriatric Assessment Team and Restorative Care}

Elderly patients who are functionally impaired should be referred for geriatric assessment. Some of these patients may require admission to a geriatric rehabilitation centre after the pneumonia has resolved. Studies have shown that geriatric assessment teams do improve the care of the elderly, resulting in a reduction in number of patients who need discharge to long-term care institutions.(72)

\section{Do-Not-Resuscitate Status}

An in-depth discussion of Do Not Resuscitate (DNR) issues is beyond the scope of this article. In a study of the epidemiology of DNR orders, Wenger et al(73) noted that more DNR orders were received for patients with greater sickness at admission and functional impairment. DNR orders were assigned more often to older patients, women and patients with dementia or incontinence and were assigned less often to black patients, patients with Medicaid and patients treated in rural hospitals. The high in-hospital mortality rates and the presence of comorbidities that often indicate the futility of resuscitation efforts dictate that physicians who manage pneumonia in elderly patients should be aware of any advance directives that their patients may have made.

\section{Nutritional Assessment}

From the age of 30 years to the age of 80 years, energy expenditure decreases by one-third. However, the requirements for protein intake do not. Malnutrition has been identified as a risk factor for development of CAP in the elderly. A recent study of malnutrition in hospitalised elderly patients with CAP showed that only $16 \%$ of the 101 patients studied were characterised as well-nourished at the time of hospital admission, in comparison to $47 \%$ of the control population. (74) Psychological factors in this group that can contribute to poor oral intake include depression, dementia and lack of motivation.

It is important to be able to identify nutritional risk in an elderly person who presents with CAP. The cornerstone of identifying nutritional risk is obtaining a weight history. Weight loss of $110 \%$ of usual weight is associated with a very high mortality rate and is considered significant. A loss of $5 \%-10 \%$ of usual weight is considered potentially important. Loss of $<5 \%$ of usual weight is considered not to be significant. Another way to determine body composition and nutritional status is to consider the body mass index ([weight in $\mathrm{kg}$ / height in $\mathrm{mt}^{2}$ ). A body mass index of $21-25$ is considered normal. In the previously cited study by Riquelme et al,(74) elderly patients with a lower body mass index is associated with an increase in nutritional risk and ultimately an increased risk of CAP. Serum albumin level is commonly cited as a marker of nutritional status and it has been correlated independently with a higher case fatality rate among persons with CAP.(75)

Hedlund et al in a study of 97 patients with pneumonia found that a low triceps skin-fold thickness, low body mass index and high Acute Physiology and Chronic Health Evaluation (APACHE) II score correlated with death within 6 months.

\section{Impaired Renal and Hepatic Function}

The elderly have impaired function of many organs by virtue of the aging process and as a result of comorbidity. Physicians should pay careful attention to drug dosages and drug interactions in this group of patients.

\section{Preventive Aspects \\ Prevention of the Next Episode of Pneumonia}

Those who are at risk for aspiration should be positioned at a $45^{\circ}$ angle when eating and should receive pureed foods. Nasogastric or percutaneous gastrostomy feeding tubes do not prevent aspiration and indeed may predispose to it, unless protocols to prevent aspiration in these settings are followed. Since tobacco smoking increases the risk of 
pneumonia, all tobacco smokers should be given advice and help to stop smoking.

\section{Vaccination}

Both influenza and pneumococcal vaccinations have been shown to be beneficial in the prevention of pneumonia in the elderly.(76-78)

Two Types of Pneumococcal Vaccines are approved for use in the United States

Pneumococcal Polysaccharide Vaccine

(PPSV23) consists of capsular material from 23 pneumococcal types.

\section{Pneumococcal Conjugate Vaccine}

(PCV) consists of capsular polysaccharides from the 13 most common types that cause disease, covalently linked to a nontoxic protein that is nearly identical to diphtheria toxin.

In 2011, PCV13 was approved by the US Food and Drug Administration (FDA) for use in adults $\geq 50$ years of age, based on studies showing that PCV13 stimulated good antibody responses in adults in this age group.(79)

In 2014, the United States Advisory Committee on Immunisation Practices (ACIP) began recommending sequential administration of both PCV13 and PPSV23 for all adults $\geq 65$ years of age who have not previously received a pneumococcal vaccine.(80) The ACIP will re-evaluate their recommendations for adults $\geq 65$ years of age in 2018 and will revise them as needed.

ACIP recommends influenza vaccination annually in the elderly patients.

\section{REFERENCES}

[1] Marrie TJ, Beecroft MD, Herman-Gnjidic Z. Resolution of symptoms in patients with community acquired pneumonia treated on an ambulatory basis. J Infect 2004;49(4):302-9.

[2] Palmer RM. Acute care of the elderly: minimizing the risk of functional decline. Cleveland Clinic J Med 1995;62(2):117-28.

[3] Inouye SK, Wagner DR, Acampora D, et al. A predictive index for functional decline in hospitalized elderly medical patients. J Gen Intern Med 1993;8(12):645-52.

[4] Metlay JP, Schulz R, Li Y-H, et al. Influence of age on symptoms at presentation in patients with community-acquired pneumonia. Arch Intern Med 1997;157(13):1453-9.

[5] Koivula I, Sten M, Makela PH. Risk factors for pneumonia in the elderly. Am J Med 1994;96(4):31320.

[6] Dorff GJ, Rytel MW, Farmer SG, et al. Etiologies and characteristic features of pneumonias in a municipal hospital. Am J Med Sci 1973;266(5):349-58.

[7] Marrie TJ, Durant H, Yates L. Community-acquired pneumonia requiring hospitalization: 5-year prospective study. Rev Infect Dis 1989;11(4):586-99.

[8] Feagan BG, Marrie TJ, Lau CY, et al. Treatment and outcomes of community-acquired pneumonia at Canadian hospitals. Can Med Assoc J 2000;162(10):1415-20.
[9] Meehan TP, Fine MJ, Krumholz HM, et al. Quality of care, process and outcomes in elderly patients with pneumonia. JAMA 1997;278(23):2080-4.

[10] Janssens JP, Krause KH. Pneumonia in the very old. Lancet Infect Dis 2004;4(2):112-24.

[11] Jackson ML, Neuzil KM, Thompson WW, et al. The burden of community-acquired pneumonia in seniors: results of a population-based study. Clin Infect Dis 2004;39(11):1642-50.

[12] Kaplan V, Angus DC, Griffin MF, et al. Hospitalized community-acquired pneumonia in the elderly: ageand sex - related patterns of care and outcome in the United States. Am J Respir Crit Care Med 2002;165(6):766-72.

[13] Vila-Corcoles A, Ochoa-Gondar 0, Rodriguez-Blanco T, et al. Epidemiology of community-acquired pneumonia in older adults: a population-based study. Respir Med 2009;103(2):309-16.

[14] Kothe H, Bauer $T$, Marre $R$, et al. Outcome of community-acquired pneumonia: influence of age, residence status and antimicrobial treatment. Eur Respir J 2008;32(1):139-46.

[15] Fry AM, Shay DK, Holman RC, et al. Trends in hospitalizations for pneumonia among persons aged 65 years or older in the United States, 1998-2002. JAMA 2005;294(21):2712-9.

[16] Kaplan V, Angus DC, Griffin MF, et al. Hospitalized community-acquired pneumonia in the elderly: ageand sex - related patterns of care and outcome in the United States. Am J Respir Crit Care Med 2002;165(6):766-72.

[17] Fernandez-Sabe N, Carratala J, Roson B, et al. Community-acquired pneumonia in very elderly patients: causative organisms, clinical characteristics and outcomes. Medicine (Baltimore) 2003;82(3):15969.

[18] Bochud PY, Moser F, Erard P, et al. Communityacquired pneumonia. A prospective outpatient study. Medicine (Baltimore) 2001;80(2):75-87.

[19] Marrie TJ, Huang JQ. Epidemiology of communityacquired pneumonia in Edmonton, Alberta: an emergency department-based study. Can Respir J 2005;12(3):139-42.

[20] Mullerova H, Chigbo C, Hagan GW, et al. The natural history of community-acquired pneumonia in COPD patients: a population database analysis. Respir Med 2012;106(8):1124-33.

[21] Vinogradova Y, Coupland C, Hippisley-Cox J. Risk of pneumonia in patients taking statins: populationbased nested case-control study. Br J Gen Pract 2011;61(592):e742-8.

[22] Van de Garde EM, Hak E, Souverein PC, et al. Statin treatment and reduced risk of pneumonia in patients with diabetes. Thorax 2006;61(11):957-61.

[23] Teepe J, Grigoryan L, Verheij TJ. Determinants of community-acquired pneumonia in children and young adults in primary care. Eur Respir J 2010;35(5):1113-7. 
[24] Almirall J, Bolibar I, Serra-Prat M, et al. New evidence of risk factors for community-acquired pneumonia: a population-based study. Eur Respir J 2008;31(6):1274-84.

[25] Schnoor M, Klante T, Beckmann M, et al. Risk factors for community-acquired pneumonia in German adults: the impact of children in the household. Epidemiol Infect 2007;135(8):1389-97.

[26] Flournoy DJ, Stalling FH, Catron TL. Seasonal and monthly variation of Streptococcus pneumoniae and other pathogens in bacteremia (1961-1981). Ecol Dis 1983;2(2):157-60.

[27] Hennessy S, Bilker WB, Leonard CE, et al. Observed association between antidepressant use and pneumonia risk was confounded by comorbidity measures. J Clin Epidemiol 2007;60(9):911-8.

[28] Van de Garde EM, Souverein PC, Hak E, et al. Angiotensin-converting enzyme inhibitor use and protection against pneumonia in patients with diabetes. J Hypertens 2007;25(1):235-9.

[29] Almirall J, Rofes L, Serra-Prat M, et al. Oropharyngeal dysphagia is a risk factor for community-acquired pneumonia in the elderly. Eur Respir J 2013;41(4):923-8.

[30] Porath A, Schlaeffer F, Lieberman D. The epidemiology of community acquired Pneumonia among hospitalized patients. J Infect 1997;34(1):41-8.

[31] El-Solh AA, Sikka P, Ramadan F, et al. Etiology of severe pneumonia in the very elderly. Am J Respir Crit Care Med 2001;163(3 Pt 1):645-51.

[32] American Thoracic Society; Infectious Diseases Society of America. Guidelines for the management of adults with hospital-acquired, ventilator-associated and healthcare-associated pneumonia. Am J Respir Crit Care Med 2005;171(4):388-416.

[33] Kupronis BA, Richards CL, Whitney CG, et al. Invasive pneumococcal disease in older adults residing in longterm care facilities and in the community. J Geriatr Soc 2003;51(11):1520-5.

[34] Lim WS, Macfarlane JT. A prospective comparison of nursing home acquired pneumonia with community acquired pneumonia. Eur Respir J 2001;18(2):362-8.

[35] Janssens JP. Pneumonia in the elderly (geriatric) population. Curr Opin Pulm Med 2005;11(3):226-30.

[36] Maruyama T, Gabazza EC, Morser J, et al. CAP and NHAP in the very elderly patients. Eur Respir 2010;104(4):584-92.

[37] Valenti WM, Trudell RG, Bentley DW. Factors predisposing to oropharyngeal colonization with gram negative bacilli in the aged. $\mathrm{N}$ Engl J Med 1978;298(20):1108-11.

[38] Papazian L, Fraisse A, Garbe L, et al. Cytomegalovirus. An unexpected cause of ventilator-associated pneumonia. Anesthesiology 1996;84(2):280-7.

[39] Medina-Walpole AM, Katz PR. Nursing home-acquired pneumonia. J Am Geriatr Soc 1999;47(8):1005-15.

[40] Marrie TJ. Epidemiology of community-acquired pneumonia in the elderly. Semin Respir Infect 1990;5(4):260-8.
[41] Mandell LA, Wunderink RG, Anzueto A, et al. Infectious Diseases Society of America/American Thoracic Society consensus guidelines on the management of community-acquired pneumonia in adults. Clin Infect Dis 2007;44 Suppl 2:S27-S72.

[42] Fine MJ, Auble TE, Yealy DM, et al. A prediction rule to identify low-risk patients with community-acquired pneumonia. N Engl J Med 1997;336(4):243-50.

[43] Lim WS, van der Eerden MM, Laing R, et al. Defining community acquired pneumonia severity on presentation to hospital: an international derivation and validation study. Thorax 2003;58(5):377-82.

[44] Espana PP, Capelastegui A, Gorordo I, et al. Development and validation of a clinical prediction rule for severe community- acquired pneumonia. Am J Respir Crit Care Med 2006;174(11):1249-56.

[45] Charles PG, Wolfe R, Whitby M, et al. SMART-COP: a tool for predicting the need for intensive respiratory or vasopressor support in community-acquired pneumonia. Clin Infect Dis 2008;47(3):375-84.

[46] Rello J, Rodriguez A, Lisboa T, et al. PIRO score for community-acquired pneumonia: a new prediction rule for assessment of severity in intensive care unit patients with community-acquired pneumonia. Crit Care Med 2009;37(2):456-62.

[47] Baughman RP. Protected-specimen brush technique in the diagnosis of ventilator associated pneumonia. Chest 2000;117(4 Suppl 2):203S-6S.

[48] Torres A, El-Ebiary M. Bronchoscopic BAL in the diagnosis of VAP. Chest 2000;117(4 Suppl 2):198S202S.

[49] Sirvent JM, Vidaur L, Gonzalez S, et al. Microscopic examination of intracellular organisms in protected bronchoalveolar mini-lavage fluid for the diagnosis of ventilator-associated pneumonia. Chest 2003;123(2):518-23.

[50] Anzueto A, Niederman MS, Pearle J, et al. CommunityAcquired Pneumonia Recovery in the Elderly (CAPRIE): efficacy and safety of moxifloxacin therapy versus that of levofloxacin therapy. Clin Infect Dis 2006;42(1):73-81.

[51] Rubinstein E, Camm J. Cardiotoxicity of fluoroquinolones. J Antimicrob Chemother 2002;49(4):593-6.

[52] Hidron AI, Low CE, Honing EG, et al. Emergence of community-acquired methicillin resistant Staphylococcus aureus strain USA300 as a cause of necrotising community-onset pneumonia. Lancet Infect Dis 2009;9(6):384-92.

[53] Rodriguez A, Mendia A, Sirvent JM, et al. Combination antibiotic therapy improves survival in patients with community-acquired pneumonia and shock. Crit Care Med 2007;35(6):1493-8.

[54] Restrepo MI, Mortensen EM, Waterer GW, et al. Impact of macrolide therapy on mortality for patients with severe sepsis due to pneumonia. Eur Respir J 2009;33(1):153-9.

[55] Giamarellos-Bourboulis EJ. Immunomodulatory therapies for sepsis: unexpected effects with macrolides. Int J Antimicrob Agents 2008;32 Suppl 1:S39-S43. 
[56] Metersky ML, Ma A, Houck PM, et al. Antibiotics for bacteremic pneumonia: improved outcomes with macrolides but not fluoroquinolones. Chest 2007;131(2):466-73.

[57] Bodi M, Rodriguez A, Sole-Violan J, et al. Antibiotic prescription for community - acquired pneumonia in the intensive care unit: impact of adherence to Infectious Diseases Society of America guidelines on survival. Clin Infect Dis 2005;41(12):1709-16.

[58] Dean NC, Silver MP, Bateman KA, et al. Decreased mortality after implementation of a treatment guideline for community-acquired pneumonia. Am J Med 2001;110(6):451-7.

[59] Mortensen EM, Restrepo M, Anzueto A, et al. Effects of guideline-concordant antimicrobial therapy on mortality among patients with community-acquired pneumonia. Am J Med 2004;117(10):726-31.

[60] Menendez R, Torres A, Zalacain R, et al. Guidelines for the treatment of community-acquired pneumonia: predictors of adherence and outcome. Am J Respir Crit Care Med 2005;172(6):757-62.

[61] Ramirez JA, Srinath L, Ahkee S, et al. Early switch from intravenous to oral cephalosporins in the treatment of hospitalized patients with Community acquired pneumonia. Arch Intern Med 1995;155(12):1273-6.

[62] Castro-Guardiola A, Viejo-Rodriguez AL, Soler-Simon $S$, et al. Efficacy and Safety of oral and early-switch therapy for community-acquired pneumonia: a randomized controlled trial. Am J Med 2001;111(5):367-74.

[63] Halm EA, Switzer GE, Mittman BS, et al. What factors influence physicians' decisions to switch from intravenous to oral antibiotics for communityacquired pneumonia? J Gen Intern Med 2001;16(9):599-605.

[64] Rizzato G, Montemurro L, Fraioli P, et al. Efficacy of a three day course of azithromycin in moderately severe community-acquired pneumonia. Eur Respir J 1995;8(3):398-402.

[65] Tellier G, Niederman MS, Nusrat R, et al. Clinical and bacteriological efficacy and safety of 5 and 7 day regimens of telithromycin once daily compared with a 10 day regimen of clarithromycin twice daily in patients with mild to moderate community-acquired pneumonia. J Antimicrob Chemother 2004;54(2):51523.

[66] Dunbar LM, Wunderink RG, Habib MP, et al. High-dose, short-course levofloxacin for community-acquired pneumonia: a new treatment paradigm. Clin Infect Dis 2003;37(6):752-60.

[67] Garcia-Vidal C, Calbo E, Pascual V, et al. Effects of systemic steroids in patients with severe communityacquired pneumonia. Eur Respir J 2007;30(5):951-6.

[68] Laterre PF, Garber G, Levy H, et al. Severe communityacquired pneumonia as a cause of severe sepsis: data from the PROWESS study. Crit Care Med 2005;33(5):952-61.
[69] The Acute Respiratory Distress Syndrome Network, Brower RG, Matthay MA, et al. Ventilation with lower tidal volumes as compared with traditional tidal volumes for acute lung injury and the acute respiratory distress syndrome. $\mathrm{N}$ Engl J Med 2000;342(18):1301-8.

[70] Tleyjeh IM, Kashour T, Hakim FA, et al. Statins for the prevention and treatment of infections: a systematic review and meta-analysis. Arch Intern Med 2009;169(18):1658-67.

[71] MacKnight C, Rockwood K. A hierarchical assessment of balance and mobility. Age Aging 1995;24(2):126-30.

[72] Landefeld CS, Palmer RM, Kresevic DM, et al. A randomized trial of care in a hospital medical unit designed to improve the functional outcomes of acutely ill older patients. $\mathrm{N}$ Engl J Med 1995;332(20):1338-44.

[73] Wenger NS, Pearson ML, Desmond KA, et al. Epidemiology of do-not resuscitate orders: disparity by age, diagnosis, gender, race and functional impairment. Arch Intern Med 1995;155(19):2056-62.

[74] Riquelme R, Torres A, El-Ebiary M, et al. Communityacquired pneumonia in the elderly. Clinical and nutritional aspects. Am J Respir Crit Care Med 1997;156(6):1908-14.

[75] Hedlund J, Hannson LO, Ortqvist A. Short- and longterm prognosis for middle-aged and elderly patients hospitalized with community-acquired pneumonia: impact of nutritional inflammatory factors. Scan J Infect Dis 1995;27(1):32-7.

[76] Potter J, Stott DJ, Roberts MA, et al. Influenza vaccination of health care workers in long-term-care hospitals reduces the mortality of elderly patients. J Infect Dis 1997;175(1):1-6.

[77] Ortqvist A, Hedlund J, Burman LA, et al. Randomised trial of 23-valent pneumococcal capsular polysaccharide vaccine in prevention of pneumonia in middle-aged and elderly people. Swedish Pneumococcal Vaccination Study Group. Lancet 1998;351(9100):399-403.

[78] Nichol KL, Baken L, Wuorenma J, et al. The health and economic benefits associated with pneumococcal vaccination of elderly people with chronic lung disease. Arch Intern Med 1999;159(20):2437-42.

[79] Centers for Disease Control and Prevention (CDC) Licensure of 13-valent pneumococcal conjugate vaccine for adults aged 50 years and older. Morb Mortal Wkly Rep 2012;61(21):394-5.

[80] Tomczyk S, Bennett NM, Stoecker C, et al. Use of 13valent pneumococcal conjugate vaccine and 23 -valent pneumococcal polysaccharide vaccine among adults aged $\geq 65$ years: recommendations of the Advisory Committee on Immunization Practices (ACIP). Morb Mortal Wkly Rep 2014;63(37):822-5. 